\title{
Veterinary Pharmacology: Is it Still Pharmacology's Cinderella?
}

\section{Mario Giorgi*}

Veterinary Clinics Department, University of Pisa, Via Livornese (lato monte), Pisa, Italy

Nowadays, pets are treated as members of the family and pet owners demand the same level of care they expect for themselves. This change in attitude has resulted in a push for the development of more effective and innovative veterinary therapies [1-3]. Animals with conditions that until recently would have resulted in euthanasia, are increasingly being successfully treated [4]. More and more, new categories of disease e.g. behavioural disease are being recognized in animals and this has stimulated pharmaceutical companies to market drugs developed specifically for animal use (Eli Lilly, Reconcile, Fluoxetine). The veterinary drug market has grown exponentially compared to the human drug market and the growth continues, even in this period of worldwide economical crisis.

There is also much scope for the use of domestic species as animal models of human disease and here again; veterinary pharmacology has a significant role to play. Companion animals are now living longer and so are more commonly manifesting age-related diseases of medical importance such as cancer, arthritis and metabolic disorders. They also share other life style, similarities that make them more suitable animal models than many of the traditionally used laboratory animals that can have drug resistance profiles that are quite different to those in humans. Laboratory animals are also short lived (months or few years) which limits their applicability for long-term drug studies and means that cancer needs to be artificially-induced. In other words, these models do not provide good simulations of human disease. This realization has prompted the merging of some US veterinary hospitals into a special consortium where they use dogs with neoplasia as models for testing human drugs. These pioneers will rapidly produce results that will be useful for both the human and veterinary fields.

Providing adequate food supply to meet the demands of a growing population is another challenge for this century. Thanks to the work of veterinary pharmacologists, we have a large number of food producing animals, bred in optimized conditions supplying a large amount of food derivates (milk, eggs, meat, honey, fish). Public perception of drugs administration to food producing animals is still negative, but in reality, rational and controlled use of the veterinary drugs produces foodstuffs that are safe for consumption.

Veterinary pharmacology still has a reduced drug armamentarium however; human drugs are increasingly being investigated for veterinary use in order to address this shortfall [5]. This is a long and complicated endeavor because of differences in the expression of enzymes, receptors and signal transduction molecules between species, but this challenge can be overcome with the cooperation of human pharmacologists. The veterinary profession, a small subpopulation in the world of medical research, has-somewhat involuntarily-acquired the skills to cooperate with and endorse the achievements of other disciplines. Hence, I suggest human pharmacologists join their veterinary colleagues in facing these challenges. This will be of mutual benefit for both fields. I am confident that Clinical \& Experimental Pharmacology will encourage mutually beneficial research as the line between veterinary and medical pharmacology becomes increasingly blurred. I hope to read many interesting manuscripts in the near future.

\section{References}

1. Giorgi M (2012) Tramadol vs tapentadol: a new horizon in pain treatment? American Journal of Animal and Veterinary Sciences 7: 7-11.

2. Giorgi M, Yun H (2011) Pharmacokinetics of mirtazapine and its main metabolites in beagle dogs: a pilot study. Vet J 192: 239-241.

3. Giorgi M, Saccomanni G, Del Carlo S, Manera C, Lavy E (2012) Pharmacokinetics of intravenous and intramuscular parecoxib in healthy beagles. Vet J 193: 246-250

4. Marchetti V, Giorgi M, Fioravanti A, Finotello R, Citi S, et al. (2012) Firstline metronomic chemotherapy in a metastatic model of spontaneous canine tumours: a pilot study. Invest New Drugs 30: 1725-1730.

5. Lavy E, Prise U, Soldani G, Neri D, Brandriss N, et al. (2011) Pharmacokinetics of methylphenidate after oral administration of immediate and sustainedrelease preparations in Beagle dogs. Vet $\mathrm{J}$ 189: 336-340.
*Corresponding author: Mario Giorgi, Veterinary Clinics Department, University of Pisa, Pisa, Italy, Tel: +39-0-50-2210154, Fax: +39-0-50-2210182; E-mail: mgiorgi@vet.unipi.it

Received August 16, 2012; Accepted August 16, 2012; Published August 19 2012

Citation: Giorgi M (2012) Veterinary Pharmacology: is it Still Pharmacology's Cinderella? Clin Exp Pharmacol 2:e103. doi:10.4172/2161-1459.1000e103

Copyright: (c) 2012 Giorgi M. This is an open-access article distributed under the terms of the Creative Commons Attribution License, which permits unrestricted use, distribution, and reproduction in any medium, provided the original author and source are credited. 